\title{
The Igf2as Transcript is Exported into Cytoplasm and Associated with Polysomes
}

\author{
Carolina Duart-Garcia • Martin H. Braunschweig
}

Received: 3 November 2011/ Accepted: 12 September 2012/Published online: 30 October 2012

(C) Springer Science+Business Media New York 2012

\begin{abstract}
Murine insulin-like growth factor 2 antisense (Igf2as) transcripts originate from the opposite strand of the same Igf2 locus as the Igf2 sense mRNA. The Igf2, insulin 2 (Ins2), and $H 19$ genes form a cluster of imprinted genes on chromosome 7. Loss of imprinting of IGF2 in humans is associated with BeckwithWiedemann syndrome and Silver-Russell syndrome, as well as with Wilm's tumor and colorectal cancer. We developed a RNA-FISH protocol to detect Igf 2 as and Igf2 transcripts. The results from the RNA-FISH were confirmed with quantitative realtime PCR and clearly indicate that the Igf2as transcripts are predominantly located in the cytoplasm of $\mathrm{C} 2 \mathrm{C} 12$ cells. In a polysome association study, we showed that the Igf 2 as sedimented with polysomes in a sucrose gradient. The cellular localization of Igf2as transcripts together with polysome fractionation analysis provides compelling evidence that the Igf $2 a$ s is protein coding.
\end{abstract}

Keywords Igf2as $\cdot$ RNA-FISH $\cdot \mathrm{C} 2 \mathrm{C} 12$ cells $\cdot$ Genomic imprinting · Polysome analysis

\section{Introduction}

Genomic imprinting is a phenomenon resulting in a parent-of-origin specific gene expression (Reik and Walter 2001). Imprinted genes are controlled by imprinting control regions (ICRs) as well as cis-acting long noncoding RNA such as Xist, Kcnq1ot1, and Air (Bartolomei and Ferguson-Smith 2011; Mohammad et al. 2009). The ICRs carry parental specific epigenetic modifications including DNA methylation that are acquired during primordial germ cell development and

C. Duart-Garcia · M. H. Braunschweig ( $\square)$

Institute of Genetics, Vetsuisse Faculty, University of Bern, Bremgartenstrasse 109a,

3001 Berne, Switzerland

e-mail: martin.braunschweig@vetsuisse.unibe.ch 
maintained after fertilization (Pauler et al. 2007). The insulin-like growth factor 2 gene $(\operatorname{Ig} f 2)$ encodes for the insulin-like growth factor-II peptide, a growth factor with a principal function in myogenesis (Florini et al. 1991, 1996). The Igf2 peptide is a member of the insulin-like growth factor (IGF) family. IGFs stimulate many anabolic responses in myoblasts and stimulate both proliferation and differentiation of the myoblasts (Florini et al. 1996). The $I g f 2$ gene was one of the first genes reported to be imprinted. Only the paternal allele of $I g f 2$ is expressed, leading to functional hemizygosity. This was proven by generating chimeric mice that had one of the $I g f 2$ alleles disrupted. Heterozygous offspring from male $I g f 2$ mutant mice were $60 \%$ smaller than the wildtype mice, demonstrating the importance of Igf2 for embryonic and fetal growth (De Chiara et al. 1990, 1991). Igf2, insulin 2 (Ins2), and $H 19$ are located in a gene cluster that maps to the distal region of mouse chromosome 7 (Monk et al. 2006). H19 is maternally expressed, whereas Igf2 and Ins 2 are paternally expressed. An ICR about $2 \mathrm{~kb}$ upstream of $\mathrm{H} 19$ is involved in the control of these reciprocally imprinted genes. This ICR is methylated on the paternal allele, which impairs the binding of the CCCTC-binding factor (CTCF or 11-zinc finger protein), leading to paternal Igf2 expression. On the maternal chromosome, CTCF binds to the unmethylated ICR, which functions as an insulator blocking the interaction between Igf2 promoters and enhancers downstream of H19 (Bell and Felsenfeld 2000; Hark et al. 2000).

The first IGF2AS transcript was found in chicken embryo while studying IGF2 expression (Taylor et al. 1991). This IGF2AS transcript overlapped IGF2 in the second coding exon. Taylor et al. (1991) suggested that this antisense transcript may be responsible for low amounts of $I G F 2$ transcripts in embryos, considering the high expression level of $I G F 2$ transcript after birth. Later, Rivkin et al. (1993) reported the first Igf2as transcripts in mice. A detailed study revealed multiple Igf2 sense and antisense transcripts including differential DNA methylation and tandem repeats at the mouse Igf2 locus (Moore et al. 1997). No open reading frame could be identified in these antisense transcripts, and their function remains elusive.

The IGF2 imprinted locus is still intensively studied, since it is implicated in Beckwith-Wiedemann syndrome and Silver-Russell syndrome, as well as in Wilm's tumor and colorectal cancer (Okutsu et al. 2000; Reik and Walter 2001; Monk et al. 2006; Berteaux et al. 2008). In this study, we investigated the localization of Igf2as transcripts in $\mathrm{C} 2 \mathrm{C} 12$ myoblast cells relative to Igf2 sense transcripts, and subsequently we performed a polysome association study. We report here for the first time that the Igf2as transcripts are present in the cytoplasm and are located in RNA-associated polysome fractions from $\mathrm{C} 2 \mathrm{C} 12$ myoblast cells, suggesting that these transcripts are protein coding.

\section{Materials and Methods}

\section{Cell Culture}

C2C12 muscle myoblast cells from Mus musculus (American Type Culture Collection) were grown in Dulbecco's Modified Eagle's Medium supplemented 
with $10 \%$ fetal calf serum and penicillin-streptomycin solution to a final concentration of $1 \%$. The cells were incubated at $37{ }^{\circ} \mathrm{C}$ in a $5 \% \mathrm{CO}_{2}$ atmosphere and were subcultured every 2 days with new medium. The procedure for subculturing $\mathrm{C} 2 \mathrm{C} 12$ cells was as follows: discarding of old culture medium, washing with phosphate buffered saline (PBS), addition of $2 \mathrm{ml} 5 \times$ trypsin-EDTA solution, and incubation at $37{ }^{\circ} \mathrm{C}$ until the cells were detached from the bottom of the flask (about $5 \mathrm{~min}$ ). Fresh growth medium (at $37^{\circ} \mathrm{C}$ ) was then added to these cells, and approximately $1.5 \times 10^{5}-1 \times 10^{6} \mathrm{C} 2 \mathrm{C} 12$ cells were transferred to a new flask and completed with growth medium to $10 \mathrm{ml}$.

\section{RNA-FISH}

Total RNA was isolated using Trizol reagent according to the manufacturer's instructions (Invitrogen) and treated with DNaseI (Ambion). RNA was then cleaned up with an RNeasy Mini Kit (Qiagen). The reverse transcription of RNA was performed with a First-Strand cDNA Synthesis Kit (GE Healthcare). The sequences of the RNA-FISH probes were selected following the recommendations of Arvey et al. (2010). The mouse Igf2as transcript sequence (accession no. NR_002855.2) was analyzed for repetitive elements using the Repeatmap program (http:// cbio.mskcc.org/ aarvey/repeatmap/). A sequence of about 500 bp was then chosen to design a primer pair (http://frodo.wi.mit.edu/primer3; Table 1). The probe sequence to detect Igf2 transcripts was selected from the coding sequence that is common for all known transcript variants (NM_010514.3). Locations of probes are shown in Fig. 1.

For the probe construction, the respective fragments for Igf2 and Igf2as were PCR amplified using cDNA from $\mathrm{C} 2 \mathrm{C} 12$ cells. The PCR products were subsequently cloned into pCRII-TOPO vectors according to the manufacturer's instructions (Invitrogen). Chemically competent cells were transformed and incubated overnight on agar plates. White colonies were then picked for further

Table 1 Primer pairs used to amplify the sequences for RNA-FISH probes and qPCR

\begin{tabular}{|c|c|c|c|}
\hline Primer & Forward sequence & Reverse sequence & $\begin{array}{l}\text { Product } \\
\text { size }(b p)\end{array}$ \\
\hline Igf 2 antisense & $\begin{array}{l}\text { 5'GTTTGCAGAGTGCACACAA } \\
\text { AGTGG3' }\end{array}$ & $\begin{array}{l}\text { 5'CCTGGCAAAGTCCAGGAG } \\
\text { TTCATCT3' }\end{array}$ & 350 \\
\hline Igf 2 sense & $\begin{array}{l}\text { 5'TGGGCAAGTTCTTCCAATAT } \\
\text { GACACC } 3^{\prime}\end{array}$ & $\begin{array}{l}\text { 5'TCTTAGTGTGGGACGTGAT } \\
\text { GGAACTG3' }\end{array}$ & 305 \\
\hline Igf2_negative & $\begin{array}{l}\text { 5'TGGGCAAGTTCTTCCAATA }^{\prime} \text { TGACACC } 3^{\prime} \\
\text { TGA }\end{array}$ & $\begin{array}{l}\text { 5'TCTTAGTGTGGGACGTGAT } \\
\text { GGAACTG3' }\end{array}$ & 305 \\
\hline Sense-Igf2_f/r & $\begin{array}{l}\text { 5'TGGGCAAGTTCTTCCAATA } \\
\text { TG3' }^{\prime}\end{array}$ & $\begin{array}{l}\text { 5'CTTTGAGCTCTTTGGCAA } \\
\text { GC3' }\end{array}$ & 114 \\
\hline Igf2as_f/r & $\begin{array}{l}\text { 5'CACCAACATGAGGATTGC } \\
\text { AC } 3^{\prime}\end{array}$ & $\begin{array}{l}\text { 5'AGGTCAGACAGCTCCAGA } \\
\text { GG3' }^{\prime}\end{array}$ & 99 \\
\hline Xist_f/r & $\begin{array}{l}\text { 5'ACAGCAGTTCTCCCAGCA } \\
\text { TT3' }\end{array}$ & $\begin{array}{l}\text { 5'CCAGGCAATCCTTCTTCT } \\
\text { TG3 }{ }^{\prime}\end{array}$ & 188 \\
\hline
\end{tabular}



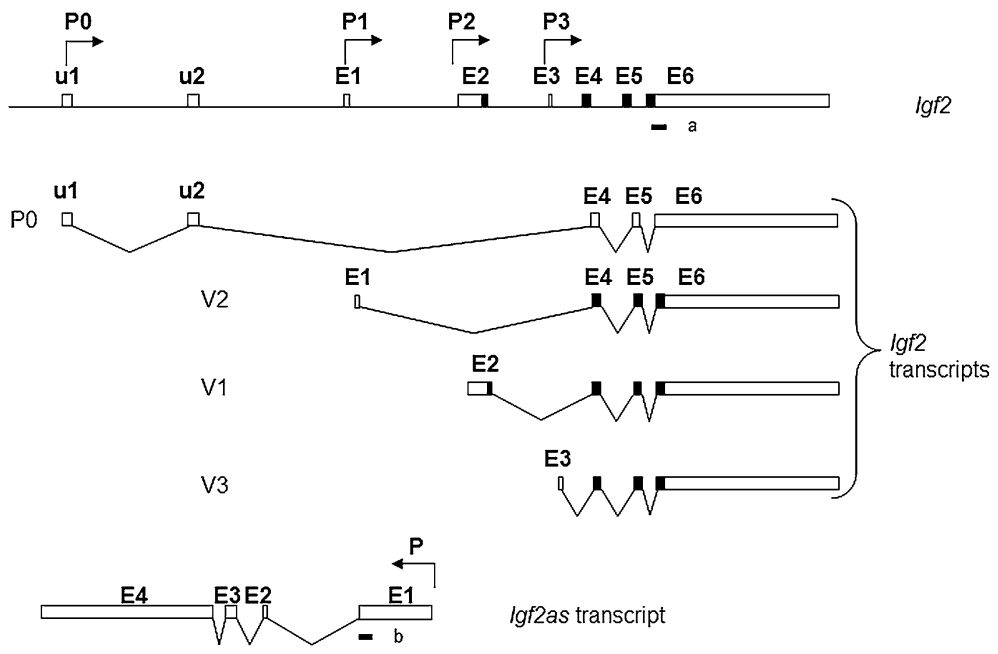

Fig. 1 Structure of the mouse Igf2 gene and the region coding for Igf2 antisense transcripts. Arrows indicate the four promoters (P0, P1, P2, and P3) for the $\operatorname{Igf} 2$ gene and the promoter (P) for the Igf2 antisense transcript. Eight exons are indicated in the $I g f 2$ gene, and four exons are shown in the $I g f 2$ antisense transcript. V1, V2, and V3 indicate the three transcript variants of the Igf2 sense transcripts. Coding exons are shown in black. The FISH probes are labeled with lowercase "a" (for Igf2) and lowercase "b" (for Igf2as)

inspections. Plasmids were extracted with the QIAprep Spin Miniprep Kit according to the manufacturer's recommendation (Qiagen). Plasmids were Sanger-sequenced using the BigDye Terminator v3.1 Ready Reaction Cycle Sequencing kit and run on the ABI 3730 capillary sequencer (Applied Biosystems).

Circular plasmid DNA was opened with restriction endonucleases Not I (New England Biolabs). The digested plasmids were extracted with phenol-chloroform and precipitated with ethanol, and the concentration was measured with the NanoDrop ND-1000 Instrument (NanoDrop Technologies).

The in vitro transcription reaction used $1 \mu \mathrm{g}$ of plasmid DNA for each Igf2as, Igf2, and negative Igf 2 control probe to synthesize the corresponding labeled RNAFISH probe. The in vitro transcription was performed with a Maxiscript kit (Ambion) using digoxigenin (DIG) RNA labeling mix (Roche) according to the manufacturer's protocol. The RNA-labeled probes were DNase digested to remove plasmid DNA and subsequently cleaned using the RNeasy Mini Kit (Qiagen).

\section{RNA-FISH Procedure}

C2C12 cells were grown on glass coverslips coated with poly-L-lysine to reach 90-95\% confluence. The cells were fixed with $4 \%$ paraformaldehyde in PBS at room temperature for $20 \mathrm{~min}$, then digested with $0.1 \%$ Proteinase K (Sigma) in $5 \%$ Tris- $\mathrm{HCl}$ and $1.5 \% \mathrm{CaCl}_{2}$ preheated buffer $\left(37{ }^{\circ} \mathrm{C}\right)$ for $5 \mathrm{~min}$ at $37{ }^{\circ} \mathrm{C}$. After digestion, the cells were again fixed for $5 \mathrm{~min}$ in $4 \%$ paraformaldehyde and subsequently washed at room temperature for $2 \mathrm{~min}$ in $2 \times$ SSC buffer. 
Once the cells were fixed, they were incubated with prehybridization buffer containing $50 \%$ formamide, $5 \times \mathrm{SSC}$, and $0.1 \%$ Tween- 20 , during $1 \mathrm{~h}$ at $50{ }^{\circ} \mathrm{C}$. The cells were then hybridized with prehybridization buffer containing $100 \mu \mathrm{g} / \mathrm{ml}$ fragmented salmon sperm DNA and $50 \mu \mathrm{g} / \mathrm{ml}$ heparin (Sigma) and using $1 \mu \mathrm{g} / \mathrm{ml}$ of the labeled probe. After the RNA probes were added, the probe mixture was heated to $80-85{ }^{\circ} \mathrm{C}$ for $2-3 \mathrm{~min}$ and then chilled on ice. After the hybridization mix was added to the fixed cells, the coverslips were covered with Gel Bond film (Bioproducts), sealed with rubber cement (Starkey), and incubated overnight at $50{ }^{\circ} \mathrm{C}$.

The slides were washed with prehybridization buffer that was preheated to $55^{\circ} \mathrm{C}$ and incubated at $55{ }^{\circ} \mathrm{C}$ for $1 \mathrm{~h}$. A second wash at room temperature was made with $50 \%$ PBT $(1 \times$ PBS, $0.1 \%$ Tween-20) and $50 \%$ hybridization solution for $10 \mathrm{~min}$, followed by a PBT washing step for $15 \mathrm{~min}$. The fixed cells on the coverslips were blocked with western blocking reagent diluted 1:4 in PBT (Roche) for $30 \mathrm{~min}$. The primary sheep anti-DIG antibody (Roche) stock solution was centrifuged at $500 \times g$ before use and diluted in western blocking reagent-PBT to 1:200. The cells were then incubated with this primary antibody for $1.5 \mathrm{~h}$ at room temperature. The slides were washed two times for $15 \mathrm{~min}$ in PBT and again incubated in western blocking reagent diluted 1:4 in PBT for $30 \mathrm{~min}$. The stock solution of Alexa 555 donkey anti-sheep secondary antibody (Invitrogen) was also centrifuged briefly and then diluted in 1:4 blocking reagent-PBT solution in the ratio of 1:300. The slides were subsequently incubated with the diluted secondary antibody for $1 \mathrm{~h}$ at room temperature. Because of the light sensitivity of Alexa 555, the slides were thereafter protected from light. The slides were washed four times using PBT for $15 \mathrm{~min}$. The nuclei were stained with TOTO3 (Invitrogen) for $30 \mathrm{~min}$ at room temperature and rinsed twice with PBT. The coverslips with the cells were mounted in prewarmed $\left(50{ }^{\circ} \mathrm{C}\right)$ Glicergel (Dako) on new slides.

Fluorescent signals were visualized using an Olympus Fluoview FV1000 microscope with epifluorescence. Pictures were taken and analyzed using the FV10-ASW 1.7 Viewer software. They were further processed using Corel PhotoPaint $\times 4$ software.

\section{Quantification of RNA in Nucleus and Cytoplasm}

RNA was extracted from both nuclear and cytoplasmic fractions using the Paris Kit according to the manufacturer's instructions, following the preparation of separate nuclear and cytoplasmic lysate protocol (Ambion).

RNA was DNase digested and cleaned up with the RNeasy Mini Kit (Qiagen). From the cleaned RNA fractions, cDNA was synthesized using a Quanti Tect Reverse Transcription kit, according to the manufacturer's protocol (Qiagen). For the cDNA synthesis, the same amount of RNA was used for both nuclear and cytoplasmic fractions, and $600 \mathrm{ng}$ of nuclear and $600 \mathrm{ng}$ of cytoplasmic RNA were reverse transcribed for each experiment.

The expression levels of Igf2 and Igf2as transcripts in the nuclear and cytoplasmic fractions of $\mathrm{C} 2 \mathrm{C} 12$ were quantified by qPCR using Power SYBR Green (Applied Biosystems). The expression levels were compared with two 
endogenous controls, Gapdh (accession no. NM_008084.2) in the cytoplasm and Xist (accession no. NR_001570.2) in the nucleus. The primer sequences and product sizes for quantitative SYBR Green qPCR are given in Table 1.

In the quantitative SYBR Green qPCR, the expression levels of Igf2 sense, Gapdh, and Xist were measured using $2 \mu \mathrm{l}$ cDNA, and Igf2as transcripts used $5 \mu \mathrm{l}$. The reaction was run on the 7300 Real-Time PCR System (Applied Biosystems). RNA samples from three independent fractionations of nuclear and cytoplasmic fractions were quantified by qPCR in triplicate. Data were analyzed using the SDS version 1.3.1 software, according to the guidelines from Applied Biosystems. In the graph, the results are expressed as relative amounts of transcripts, which corresponds to the cycle threshold $(\mathrm{Ct})$ values corrected for the RNA amounts used to synthesize the cDNA.

\section{Polysome Fractionation}

C2C12 cells were grown in $75 \mathrm{~cm}^{2}$ dishes to $70 \%$ confluence. One dish was treated with $100 \mu \mathrm{g} / \mathrm{ml}$ cycloheximide (Sigma) $3 \mathrm{~min}$ before harvest. A negative control plate remained without the cycloheximide treatment. The medium was then removed, and the cells were washed with cold PBS with $100 \mu \mathrm{g} / \mathrm{ml}$ cycloheximide and without it for the negative control. The cells treated with cycloheximide were harvested with $500 \mu \mathrm{l}$ polysome buffer containing $140 \mathrm{mM} \mathrm{NaCl}, 1.5 \mathrm{mM} \mathrm{MgCl}$, $10 \mathrm{mM}$ Tris- $\mathrm{HCl}$ (pH 8), $0.5 \%$ Nonidet P-40 (Roche), and RNasin (500 U/ml) on ice. The negative control cells were harvested using $400 \mu \mathrm{l}$ of a buffer with the same composition but with $0.2 \mathrm{mM} \mathrm{MgCl}$. The cells were then passed through a syringe and centrifuged at $14,000 \mathrm{rpm}$ for $5 \mathrm{~min}$ at $4{ }^{\circ} \mathrm{C}$ to pellet the nuclei. The supernatant was collected and supplemented with $665 \mu \mathrm{g} / \mathrm{ml}$ heparin, $20 \mathrm{mM}$ dithiothreitol, and $1 \mathrm{mM}$ phenylmethanesulfonyl fluoride, including $100 \mu \mathrm{g} / \mathrm{ml}$ cycloheximide for the treated cells. The samples were then centrifuged at $14,000 \mathrm{rpm}$ for $5 \mathrm{~min}$ at $4{ }^{\circ} \mathrm{C}$ to pellet the mitochondria and membrane debris. After centrifugation, $100 \mu \mathrm{l}$ of $0.5 \mathrm{M}$ EDTA was exclusively added to the $400 \mu \mathrm{l}$ supernatant of the negative control cells. The mixture was loaded on top of a $7-47 \%$ sucrose gradient and ultracentrifuged at 38,000 rpm for $2 \mathrm{~h} \mathrm{at} 4{ }^{\circ} \mathrm{C}$ in a Sorvall TH-641 rotor (Kendro). From the gradients, 10 fractions of $1 \mathrm{ml}$ were collected by puncturing the bottom of the tube. The samples were deproteinated by adding $100 \mu \mathrm{g} / \mathrm{ml}$ of Proteinase K, $1 \%$ SDS, and $10 \mathrm{mM}$ EDTA. The samples were extracted with phenol-chloroform and precipitated with ethanol. An RNA aliquot $(3 \mu \mathrm{l})$ of each polysome fraction and the EDTA-disrupted negative control fraction was analyzed on $1.2 \%$ agarose gel. The remaining $12 \mu \mathrm{l}$ of RNA was used for cDNA synthesis with the First-strand cDNA Synthesis Kit (GE Healthcare), following the manufacturer's instructions. Quantification in duplicate of Igf $2 a$ s and Gapdh transcript levels was performed by qPCR using TaqMan probes from Applied Biosystems (Table 2). For the quantification of Igf2as, a nested PCR procedure was applied by amplifying an Igf2as fragment for 10 cycles with Igf2as_outer primers followed by qPCR using Igf2as_inner primers and an Igf2as MGB probe (Table 2). The data were further analyzed. 
Table 2 Primer pairs and probes used in TaqMan qPCR experiments

\begin{tabular}{|c|c|c|c|c|}
\hline Primer & Forward sequence & Reverse sequence & Probe & $\begin{array}{l}\text { Product } \\
\text { size (bp) }\end{array}$ \\
\hline $\begin{array}{l}\text { Igf2as__ } \\
\text { outer_f/r }\end{array}$ & $\begin{array}{l}\text { 5'CCACATAGGGACTC } \\
\text { CACACC } 3^{\prime}\end{array}$ & $\begin{array}{l}\text { 5'AGGTCAGAC } \\
\text { AGCTCCAGAGG3' }^{\prime}\end{array}$ & & 181 \\
\hline $\begin{array}{l}\text { Igf2as } \\
\text { TaqMan_f/r }\end{array}$ & $\begin{array}{l}5^{\prime} \text { TGCACCAAA } \\
\text { CTGATCAACACAA3 }\end{array}$ & $\begin{array}{l}\text { 5’AAAGGCA }^{\prime} \\
\text { GGGTTCCAGATGA3' }\end{array}$ & $\begin{array}{l}\text { 5'CACACCAAAA } \\
{\text { ATTCTTTC } 3^{\prime}}^{\prime}\end{array}$ & 63 \\
\hline $\begin{array}{l}\text { Gapdh } \\
\text { TaqMan_f/r }\end{array}$ & $\begin{array}{l}\text { 5'CGGCCGCA } \\
\text { TCTTCTTGTG3' }\end{array}$ & 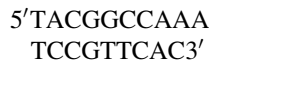 & $\begin{array}{l}\text { 5'AGTGCCAGCC } \\
\text { TCGTCCC } \\
\text { GTAGACA3 }^{\prime}\end{array}$ & 79 \\
\hline
\end{tabular}

\section{Results}

\section{Visualization of Igf2as Transcripts in C2C12 Cells}

First we aimed to determine the subcellular localization of the $\operatorname{Ig} f 2 / \operatorname{Ig} f 2 a$ s sense and antisense pair in $\mathrm{C} 2 \mathrm{C} 12$ murine myoblast cells, with the ultimate goal of establishing a function for Igf2as. We performed RNA-FISH and found that the Igf2as transcripts are predominantly located in the cytoplasm of $\mathrm{C} 2 \mathrm{C} 12$ cells (Fig. 2). Fluorescence signals were evenly distributed in the cytoplasmic compartment of all cells, but many fewer fluorescence signals were observed in the nuclei (stained in blue). The analysis of hundreds of cells clearly suggests that the Igf2as transcripts are exported into the cytoplasm. In parallel, Igf2 sense transcripts were also detected in RNA-FISH experiments. Strong fluorescence signals were homogeneously distributed in the cytoplasmic fraction of Igf2-probed C2C12 cells (Fig. 2). In all RNA-FISH experiments, a sense probe to Igf2 transcripts was routinely included as a negative control probe. The fluorescence signals observed in the RNA-FISH experiments with the negative nontarget Igf 2 control probe were very low and randomly distributed over the entire cells. Taken together, Igf 2 as is present in the cytoplasmic compartment of $\mathrm{C} 2 \mathrm{C} 12$ cells. The intensity of the signals further showed that the Igf2 sense transcript is much more abundant than the Igf2as transcript (Fig. 2).

Quantification of Transcripts in Nuclear and Cytoplasmic Fractions by qPCR

In order to confirm our RNA-FISH results and to quantify RNA transcripts in C2C12 cell fractions, we performed qPCR analysis. We separated the nuclear and cytoplasmic fractions from $\mathrm{C} 2 \mathrm{C} 12$ cells and measured the amount of Igf2 antisense transcripts in the nucleus and cytoplasm. Glyceraldehyde-3-phosphate dehydrogenase $(G a p d h)$ and $\mathrm{X}$-inactive specific transcript (Xist) were used as endogenous controls in the cytoplasmic and nuclear fractions, respectively. The level of expression is represented as relative amount of transcripts (Fig. 3). Similar to RNAFISH, the qPCR analysis showed that the Igf $2 a$ s expression was higher in the cytoplasmic fraction than in the nuclear fraction of $\mathrm{C} 2 \mathrm{C} 12$ cells. Igf2 sense 

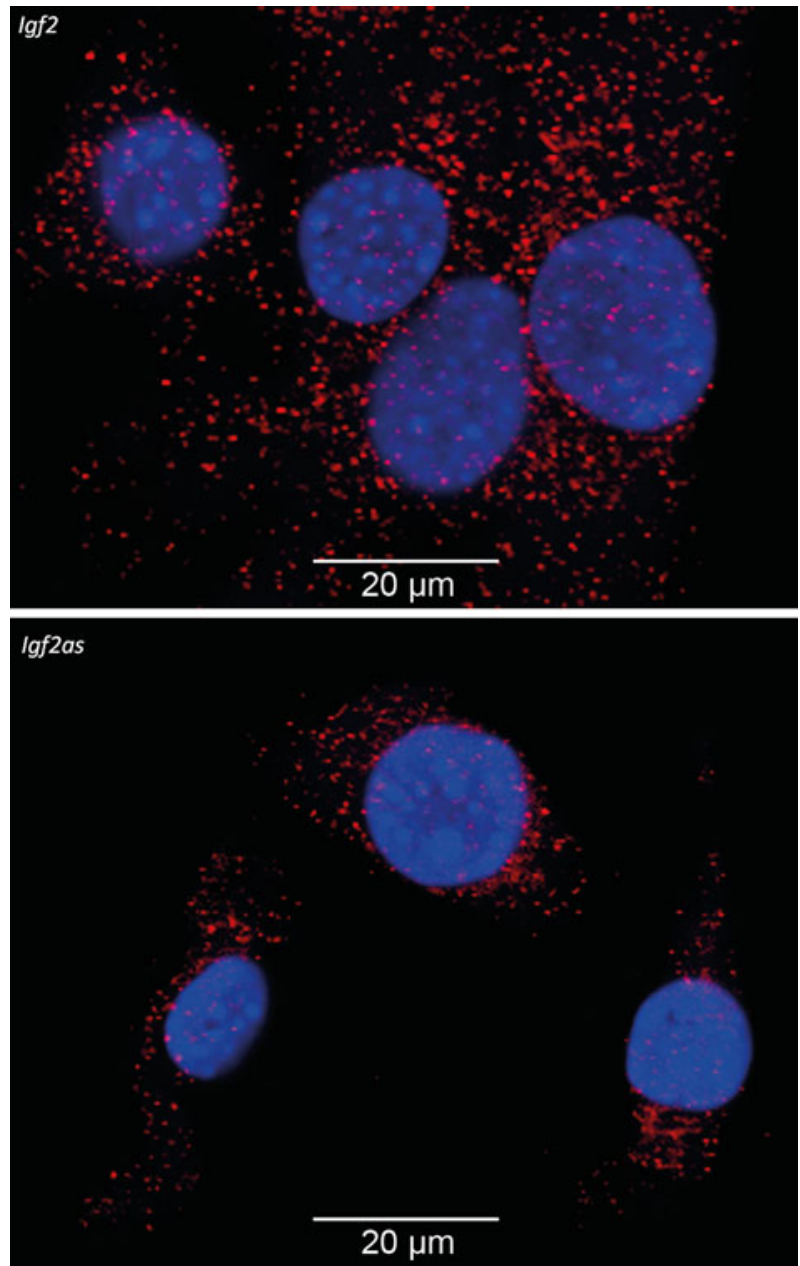

Fig. 2 RNA-FISH to detect Igf2 and Igf2as transcripts in C2C12 cells. (Top) The Igf2 probe hybridized against Igf2 sense transcripts in $\mathrm{C} 2 \mathrm{C} 12$ cells. (Bottom) The Igf2as probes hybridized against Igf2 antisense transcripts in $\mathrm{C} 2 \mathrm{C} 12$ cells. Fluorescent signals from the probes are shown as red flecks. The nuclei are stained with TOTO3 and shown as large blue round objects (Color figure online)

transcripts were more abundant in the cytoplasm than in the nuclear fraction. As expected, the Gapdh transcript level was higher in the cytoplasmic fraction. Xist transcripts appear to be predominantly located in the nuclear compartment.

\section{Polysome Association Analysis}

In order to determine whether Igf 2 as transcripts are protein coding, we performed a polysome association analysis. A positive association indicates translation of the transcripts. In this assay, we treated the cells with cycloheximide, which keeps the 


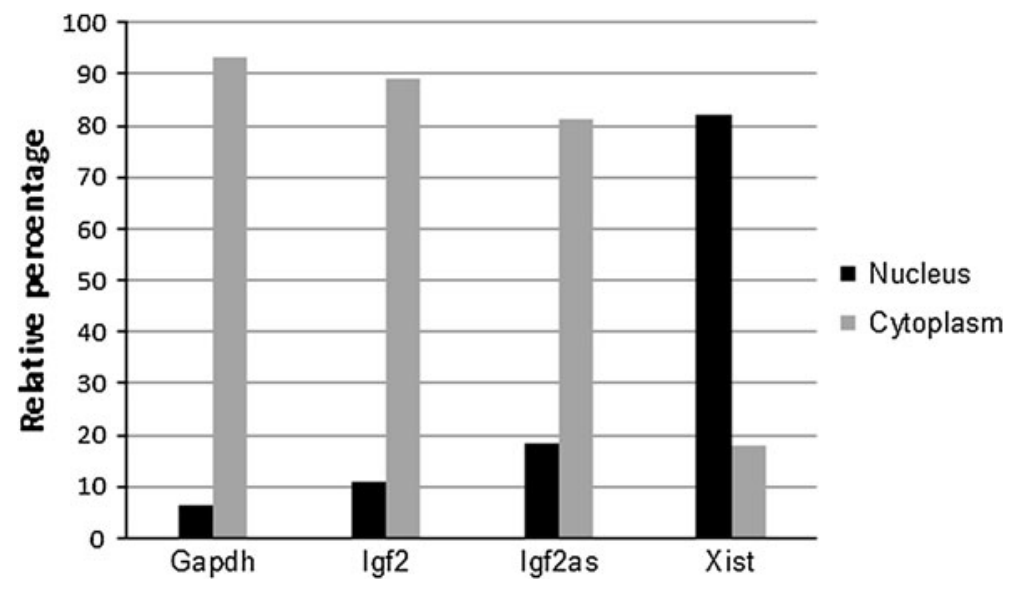

Fig. 3 Quantification of Igf2as transcripts compared with Gapdh, Igf2, and Xist expression. The results are expressed as relative amounts of transcripts. Black bars Nuclear fractions of C2C12 cells. Gray bars Cytoplasmic fractions of $\mathrm{C} 2 \mathrm{C} 12$ cells. Bars represent the mean of three replicates of one experiment

translating RNA bound to the polysomes. Following the treatment, we purified RNA-associated polysomes by sucrose gradient differential centrifugation from C2C12 cells. We included a negative control containing an EDTA-treated C2C12 lysate, which disrupts the polysomes and impairs their location in the lower fractions of the gradient. In this way, the RNA associated with the polysomes is shifted to the upper fractions; RNAs associated with other proteins will not be affected. From each sucrose gradient, 10 fractions were collected. To control the experiment and observe the polysome location throughout the fractions, we visualized the $28 \mathrm{~S}$ and $18 \mathrm{~S}$ rRNAs in an agarose gel (Fig. 4). The gel showed the distribution of $28 \mathrm{~S}$ and $18 \mathrm{~S}$ rRNA from fractions 1-6, representing the polysomal fractions. Fractions 7-10 are frequently referred to as free RNA fractions. Fractions 1-4 from the negative control experiment were free of $28 \mathrm{~S}$ and $18 \mathrm{~S}$ rRNA, indicating disruption of polysomes by EDTA. Igf 2 as transcripts were detected in the polysomal fractions in the cycloheximide-treated cells (Fig. 5). In contrast, the transcript distribution in the EDTA-treated control experiment was shifted to the upper fractions, as expected for polysome-associated transcripts. This clearly indicates that the Igf2as transcripts are bound to polysomes and released from them by EDTA. Similarly, Gapdh control transcripts were present in the polysomal fractions and underwent a distribution shift after EDTA treatment (Fig. 5).

\section{Discussion}

We found significant expression levels of Igf2as transcripts in the cytoplasm of undifferentiated $\mathrm{C} 2 \mathrm{C} 12$ cells by means of two independent analyses, RNA-FISH and cell fractionation followed by qPCR. The results strongly indicate that the Igf2as transcripts are functional rather than solely representing transcriptional noise. 


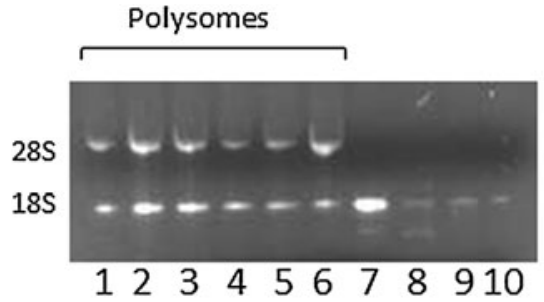

\section{Cycloheximide}

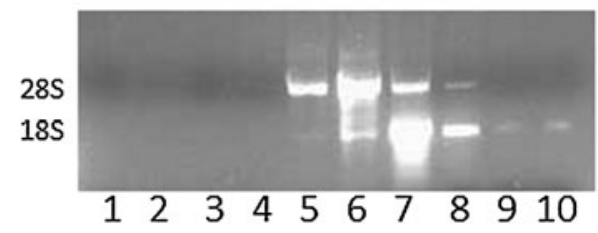

EDTA

Fig. 4 Distribution of ribosomal RNA along the sucrose gradient. The $\mathrm{C} 2 \mathrm{C} 12$ cells were treated with cycloheximide (left) or EDTA (right) and sedimented in a gradient of 7-47\% sucrose. The gradient was collected from the highest sucrose percentage (lane 1) to the lowest sucrose percentage (lane 10). In the cycloheximide treatment, the polysomal fractions are seen in lanes 1-6. In the EDTA treatment, the absence of $28 \mathrm{~S}$ and $18 \mathrm{~S}$ rRNA in those lanes indicates that the polysomes were disrupted and the ribosomes were shifted to the upper fractions
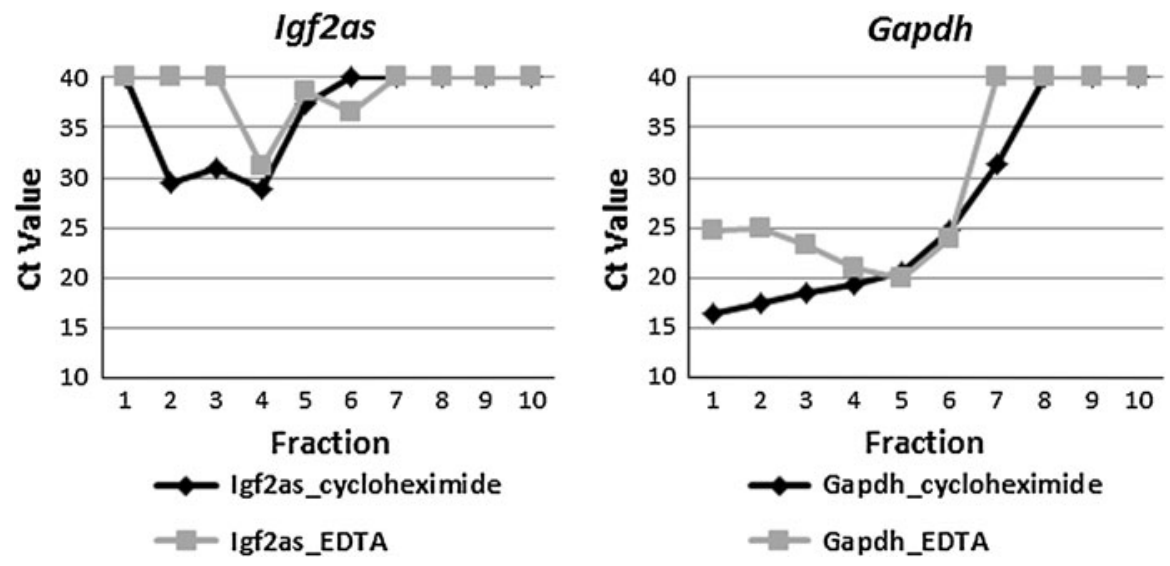

Fig. 5 Distribution of Igf2as and Gapdh transcripts along the fractions. The Igf2 antisense (left) and Gapdh (right) transcripts were quantified by qPCR for each fraction (1-10). The Ct values plotted for Igf2as and Gapdh compare the cycloheximide (black) and EDTA (gray) experiments. The release of transcripts from the polysomes is reflected in the higher $\mathrm{Ct}$ values found for the EDTA-treated C2C12 cell lysate. A Ct value of 40 corresponds to "no amplification"

Additionally, the polysome study demonstrates that the Igf2as transcripts are associated with the polysomal fraction, strongly suggesting a protein coding function of Igf2as. A recent study performing ribosome profiling provides further evidence that the Igf2as sequences were found in ribosomes (Ingolia et al. 2011). An in silico analysis of their data on ribosome footprints converted to DNA revealed numerous $40 \mathrm{bp}$ reads that map to the Igf2as sequence. We cannot exclude, however, that the Igf2as transcripts have further functions besides coding for proteins.

It is interesting that we found abundant fluorescence signals with the respective Igf 2 sense and antisense probes in all $\mathrm{C} 2 \mathrm{C} 12$ cells for each RNA-FISH experiment, which suggests co-expression of this sense/antisense pair in single cells. 
Co-expression of the Igf2/Igf2as pair would allow these two transcripts to form RNA duplexes around exon 1 of $\operatorname{Igf} 2$ variant 2 and around $\mathrm{u} 1$ of the placentaspecific transcript from promoter P0 (Fig. 1). The formation of duplexes between Igf2as and Igf2 may lead to the masking of key regulatory features within either transcript, inhibiting the access and binding of important trans-acting factors (Beiter et al. 2009; Lavorgna et al. 2004). These RNA duplexes could also enter the RNA interference pathway and direct specific destruction of target mRNAs (Wang and Carmichael 2004; Kent and MacMillan 2004). Presently, we also cannot exclude that the Igf2as could code for a miRNA, since it has previously been reported that the H19 transcript is processed into a primary miRNA transcript in both humans and mice (Cai and Cullen 2007). Alternatively, cytoplasmic long noncoding RNAs such as this Igf2as transcript can down-regulate the mRNA target by recruiting RNA decay proteins (Wang and Chang 2011).

In conclusion, our results clearly showed that the Igf2as transcripts are present in the cytoplasm and are associated with the polysome fractions. These results strongly indicate that the Igf2as is protein coding, although noncoding Igf 2 as functions are not yet formally excluded.

Acknowledgments The authors thank Philippe Plattet for technical advice and Tosso Leeb for scientific suggestions. This research was supported by the Swiss National Foundation (Project 31003A_127564).

\section{References}

Arvey A, Hermann A, Hsia CC, Ie E, Freund Y, McGinnis W (2010) Minimizing off-target signals in RNA fluorescent in situ hybridization. Nucleic Acids Res 38:e115

Bartolomei MS, Ferguson-Smith AC (2011) Mammalian genomic imprinting. Cold Spring Harb Perspect Biol 3:a002592

Beiter T, Reich E, Williams RW, Simon P (2009) Antisense transcription: a critical look in both directions. Cell Mol Life Sci 66:94-112

Bell AC, Felsenfeld G (2000) Methylation of a CTCF-dependent boundary controls imprinted expression of the Igf2 gene. Nature 405:482-485

Berteaux N, Aptel N, Cathala G, Genton C, Coll J, Daccache A, Spruyt N, Hondermarck H, Dugimont T, Curgy JJ, Forné T, Adriaenssens E (2008) A novel H19 antisense RNA overexpressed in breast cancer contributes to paternal IGF2 expression. Mol Cell Biol 28:6731-6745

Cai X, Cullen BR (2007) The imprinted H19 noncoding RNA is a primary microRNA precursor. RNA 13:313-316

De Chiara TM, Eftratiadis A, Robertson EJ (1990) A growth-deficiency phenotype in heterozygous mice carrying an insulin-like growth factor II gene disrupted by targeting. Nature 345:78-80

De Chiara TM, Robertson EJ, Efstratiadis A (1991) Parental imprinting of the mouse insulin-like growth factor II gene. Cell 64:849-859

Florini JR, Magri KA, Ewton DZ, James PL, Grindstaff K, Rotwein PS (1991) Spontaneous differentiation of skeletal myoblasts is dependent upon autocrine secretion of insulin-like growth factor-II. J Biol Chem 266:15917-15923

Florini JR, Ewton DZ, Coolican SA (1996) Growth hormone and the insulin-like growth factor system in myogenesis. Endocr Rev 17:481-517

Hark AT, Schoenherr CJ, Katz DJ, Ingram RS, Levorse JM, Tilghman SM (2000) CTCF mediates methylation-sensitive enhancer blocking activity at the H19/Igf2 locus. Nature 405:486-489

Ingolia NT, Lareau LF, Weissman JS (2011) Ribosome profiling of mouse embryonic stem cells reveals the complexity and dynamics of mammalian proteomes. Cell 4:789-802

Kent OA, MacMillan AM (2004) RNAi: running interference for the cell. Org Biomol Chem 2:1957-1961 
Lavorgna G, Dahary D, Lehner B, Sorek R, Sanderson CM, Casari G (2004) In search of antisense. Trends Biochem Sci 29:88-94

Mohammad F, Mondal T, Kanduri C (2009) Epigenetics of imprinted long noncoding RNAs. Epigenetics 4:277-286

Monk D, Sanches R, Arnaud P, Apostolidou S, Hills FA, Abu-Amero S, Murrell A, Friess H, Reik W, Stanier P, Constância M, Moore GE (2006) Imprinting of IGF2 P0 transcript and novel alternatively spliced INS-IGF2 isoforms show differences between mouse and human. Hum Mol Genet 15:1259-1269

Moore T, Constância M, Zubair M, Bailleul B, Feil R, Sasaki H, Reik W (1997) Multiple imprinted sense and antisense transcripts, differential methylation and tandem repeats in a putative imprinting control region upstream of mouse Igf2. Proc Natl Acad Sci USA 94:12509-12514

Okutsu T, Kuroiwa Y, Kagitani F, Kai M, Aisaka K, Tsutsumi O, Kaneko Y, Yokomori K, Surani MA, Kohda T, Kaneko-Ishino T, Ishino F (2000) Expression and imprinting status of human PEG8/ IGF2AS, a paternally expressed antisense transcript from the IGF2 locus, in Wilms' tumors. J Biochem 127:475-483

Pauler FM, Koerner MV, Barlow DP (2007) Silencing by imprinted noncoding RNAs: is transcription the answer? Trends Genet 23:284-292

Reik W, Walter J (2001) Genomic imprinting: parental influence on the genome. Nat Rev Genet 2:21-32

Rivkin M, Rosen KM, Villa-Komaroff L (1993) Identification of an antisense transcript from the IGF-II locus in mouse. Mol Reprod Dev 35:394-397

Taylor ER, Seleiro EA, Brickell PM (1991) Identification of antisense transcripts of the chicken insulinlike growth factor-II gene. J Mol Endocrinol 7:145-154

Wang KC, Chang HY (2011) Molecular mechanisms of long noncoding RNAs. Mol Cell 43:904-914

Wang Q, Carmichael GG (2004) Effects of length and location on the cellular response to doublestranded RNA. Microbiol Mol Biol Rev 68:432-452 